\title{
Development of Macro-Porous Silicon Based Dye-Sensitized Solar Cells with Improved Light Trapping
}

\author{
Mehdi Aliaghayee, Hassan Ghafoori Fard*, and Ashkan Zandi \\ Department of Electrical Engineering, Amirkabir University of Technology, 424 Hafez Avenue,Tehran, 15875-4413, Iran
}

\begin{abstract}
The light harvesting efficiency is counted as an important factor in the power conversion efficiency of DSSCs. There are two measures to improve this parameter, including enhancing the dye-loading capacity and increasing the light trapping in the photoanode structure. In this paper, these tasks are addressed by introducing a macro-porous silicon (PSi) substrate as photoanode. The effects of the novel photoanode structure on the DSSC performance have been investigated by using energy dispersive X-ray spectroscopy, photocurrent-voltage, UV-visible spectroscopy, reflectance spectroscopy, and electrochemical impedance spectroscopy measurements. The results indicated that bigger porosity percentage of the PSi structure improved the both anti-reflective/light-trapping and dye-loading capacity properties. PSi based DSSCs own higher power conversion efficiency due to its remarkable higher photocurrent, open circuit voltage, and fill factor. Percent porosity of $64 \%$, PSi(III), resulted in nearly 50 percent increment in power conversion efficiency compared with conventional DSSC. This paper showed that PSi can be a good candidate for the improvement of light harvesting efficiency in DSSCs. Furthermore, this study can be considered a valuable reference for more investigations in the design of multifunctional devices which will profit from integrated on-chip solar power.
\end{abstract}

Keywords : Dye sensitized solar cell, Porous silicon, Electrochemical anodization, Light harvesting efficiency

Received : 12 April 2016, Accepted : 7 August 2016

\section{Introduction}

The light-harvesting efficiency (LHE) is one of the key features for high performance photovoltaic devices. This feature is derogated by reducing film thickness in thin-film solar cells such as dye sensitized solar cell (DSSC); therefore, many approaches are made to improve it. For example, porous active layer with high surface area [1-3], hierarchically nanostructures as photoanode [4-6], scattering layers on the top of active film [7-9], plasmonic photoanodes [10-12] and photonic crystal photoanodes [1315] have been applied for changing the optical design of the DSSC to optimize its light absorbance. Since the mentioned approaches have some limitations like high reflectance loss and low dye adsorption,

*E-mail address: ghafoorifard@aut.ac.ir DOI: http://dx.doi.org/10.5229/JECST.2016.7.3.218 researchers are still extensively eager to explore the new light trapping structures as photoanode.

Surface texturing is one of the most powerful techniques to improve thin film solar cell's efficiency. These textured substrates increase the LHE by: (a) reducing the probability of optical reflection of the front surface, (b) lengthening the optical path of the light through the cell, (c) trapping a greater percentage of light within the thin active layers, and (d) increasing the electrode's surface area [16-18]. In the recent years some publications have reported the employing of surface textured substrates as photoanode for DSSCs, too.

Reports of employing textured glass, patterned FTO, textured-3D $\mathrm{TiO}_{2}$ active layer, and alternative grooved substrates like Ti metal as photoanode have resulted a significant increase in conversion efficiency. Hussain et al. reported the ICP-RIE textured glass substrate as photoanode. Their textured glass 
substrate showed the high diffused transmittance and haze ratio in the visible-NIR wavelength region, which was suitable for high performance DSSCs [19]. Also, maskless RIE pre-textured glass substrates as photoanode has been introduced to DSSC by Chen et al. [20]. Another notable enhancement in power conversion efficiency was achieved through the reduction in reflections of the visible range and increasing effective cell interface area. In a study by Kong et al. a DSSC fabricated on the patterned FTO electrode and the effect of surface modification was investigated [21]. That cell showed higher photocurrent using larger surface area of the patterned FTO which allows more involvement of $\mathrm{TiO}_{2}$ particles and dyes. In 2013, Wooh et al. demonstrated a light-trapping strategy in DSCs with textured and 3D photoanodes made from $\mathrm{TiO}_{2}$ nanoparticles [22]. The novel structure showed higher light absorbance and hence higher photocurrent in comparison with the ordinary 2D flat photoanode. It is noticed that better performance was due to the increase of the light path length caused by the reflection of the scattered light on the tilted facets of the textured structures. Also, Nath et al. introduced hierarchically arranged light-scattering layers (LSLs) into the regular $\mathrm{TiO}_{2}$ films of DSSCs to enhance the LHE in the visible region of light [23]. The optical density was significantly enhanced inside the film by the effect of producing higher wavelength light gradually with an increase in scattering particle size. The power conversion efficiency of the cells with scattering layers was enhanced up to $32 \%$ for wavelengths ranging from 550 to $800 \mathrm{~nm}$ compared with cells without scattering layers. In another research a thin $\mathrm{TiO}_{2}$ underlayer with a grooved structure was prepared on a Ti metal [24]. This textured underlayer decreased the charge transfer resistance at the $\mathrm{Ti}$ metal/ $\mathrm{TiO}_{2}$ interface and importantly improved the light harvesting ability of the cell.

This research looked into the possibility of having light trapping process in DSSC by using macroporous silicon (PSi) substrate as photoanode. To the best of our knowledge, this is the first work that shows how the DSSC's performance parameters, such as short-circuit current density, open circuit voltage, fill factor, and power conversion efficiency affected by the geometric properties of porous silicon. Three different PSi samples were formed using electrochemical anodization. Afterward ITO film was deposited on PSi substrates with DC magnetron sputtering, which was followed by the subsequent deposition of a $\mathrm{TiO}_{2}$ layer by using sol-gel spin-coating. Finally, the proposed DSSCs have been assembled. An investigation including energy dispersive Xray spectroscopy, photocurrent-voltage, UV-visible spectroscopy, reflectance spectroscopy, and electrochemical impedance spectroscopy measurements has been carried out in order to characterize the suggested DSSC. PSi substrates with different textured surface changed both the optical property and dyeloading capacity which ameliorate light harvesting efficiency far better.

\section{Experimental Section}

\subsection{Preparation of Macro-Porous Silicon}

Many physical and chemical methods have been proposed for texturing of silicon surface, such as mechanical grooving [25], lithography followed by reactive ion etching [26], laser texturing [27], and electrochemical etching. Porous silicon prepared by electrochemical etching is of interest due to the ability for fabricating various structures and cost effectiveness [28,29].

In our experiments, (lll 111$)$ and ( $\left.\begin{array}{lll}1 & 0 & 0\end{array}\right)$-oriented ntype, Czochralski-grown, single crystal Si wafers with thickness of $430 \pm 20 \mu \mathrm{m}$ and resistivity of $1.5 \pm$ $0.2 \Omega \mathrm{cm}$ used as starting materials. The wafers were first cut into $1.5 \times 1.5 \mathrm{~cm}^{2}$ square samples and then samples were dipped in 1:10 dilute HF solution to remove all traces of native oxide. Before etching procedure, samples were chemically cleaned by standard RCA procedures and dried under a stream of $\mathrm{N}_{2}$ gas respectively. The PSi was prepared by electrochemical anodization method in an electrolyte of $40 \%$ hydrofluoric acid, DI water, and $99.9 \%$ ethanol [HF: $\left.\mathrm{H}_{2} \mathrm{O}: \mathrm{C}_{2} \mathrm{H}_{5} \mathrm{OH}\right]$. Ethanol is often added to the $\mathrm{HF}$ solution to reduce its surface tension. The Si sample and $\mathrm{Pt}$ disc were connected as anode and cathode respectively. Approximately $0.25 \mathrm{~cm}^{2}$ of the polished side of the Si sample was exposed to the etching solution. PSi formed by this method can present various shape and size, depending on formation parameters including current density, electrolyte concentration, and etching time. By optimizing the etching conditions, PSi samples with the pore diameter in micrometer scale were prepared. After chemical etching, the surface-processed $\mathrm{Si}$ was rinsed several 
times in ethanol and dried [30].

\subsection{Preparation of $\mathrm{TiO}_{2} \mathrm{Sol}$}

The sol-gel procedure with a titanium-alkoxide sol was used for synthesis of $\mathrm{TiO}_{2}$ sol. Titanium tetra isopropoxide (TTIP, 97\%, Sigma-Aldrich) was used as titania precursor and ethanol, nitric acid $\left(\mathrm{HNO}_{3}\right)$ and de-ionized water were used as received. First, the titanium tetra isopropoxide was mixed with ethanol, and the de-ionized water was added drop wise under constant stirring for $1 \mathrm{~h}$. Then, the resultant solution was peptized using $(0.1 \mathrm{~mol})$ nitric acid, to maintain the $\mathrm{pH}$ of the solution, and refluxed at $80^{\circ} \mathrm{C}$ for $8 \mathrm{~h}$. Finally, a white and highly viscous solution was obtained [31-33].

\subsection{Preparation of Photoanodes and DSSCs}

The prepared nanoparticle $\mathrm{TiO}_{2}$ sole was coated onto ITO-coated PSi substrates by spin-coating technique. This process was controlled by multiple spincoating and drying steps. The thickness of $\mathrm{TiO}_{2}$ films above the PSi substrates' surface was about $2 \mu \mathrm{m}$ with good filling in the micro-pores. After drying in air the $\mathrm{TiO}_{2}$ photoanodes were heated at $100{ }^{\circ} \mathrm{C}$ for $15 \mathrm{~min}$ which was followed by sintering at $400^{\circ} \mathrm{C}$ for $30 \mathrm{~min}$. The resulted photoanodes, after cooling down to $120 \mathrm{C}$, were immersed into a solution of N719 dye in ethanol for $24 \mathrm{~h}$ at room temperature for complete dye adsorption. Afterwards, the photoanodes were rinsed with anhydrous ethanol to wash redundant dye molecules away. Counter electrodes were prepared by spin-coating $4 \mathrm{wt} \% \mathrm{H}_{2} \mathrm{PtCl}_{6}$ solution onto the ITO glass and heating at $450{ }^{\circ} \mathrm{C}$ for 30 min. The dye-adsorbed $\mathrm{TiO}_{2}$ photoanodes and the Ptcoated counter electrodes were assembled into a sandwich-type cell using a clamp and sealed with a hot-melt sealant of $80 \mu \mathrm{m}$ thick. The electrolyte solution was a mixture of $\mathrm{LiI}(0.5 \mathrm{M}), \mathrm{I}_{2}(0.05 \mathrm{M})$, and 4tert-butylpyridine $(0.5 \mathrm{M})$ in acetonitrile and was injected through a drilled hole in the counter electrodes. In the next step the hole was sealed using a cover glass. The final active area of the cells was $0.25 \mathrm{~cm}^{2}$ [33]. In this work, traditional ITO glassbased photoanode was also fabricated with the same process. The thickness of $\mathrm{TiO}_{2}$ film was about $15 \mu \mathrm{m}$.

\subsection{Characterization}

In this study, porosity of the PSi samples was measured by gravimetric method. Percent porosity is defined as the fraction of voids inside the porous layer verses the starting silicon. This parameter is calculated by gravimetric technique. The original crystalline silicon sample is weighed first $\left(\mathrm{m}_{1}\right)$, then PSi is formed and the sample is weighed again $\left(\mathrm{m}_{2}\right)$, finally the PSi layer is removed and the sample is weighed once more $\left(\mathrm{m}_{3}\right)$. The selective removal of the porous Si layer-with no effect on the bulk crystalline silicon-is made by dipping for a few minutes in an aqueous solution of $\mathrm{KOH} \mathrm{(3 \%} \mathrm{in} \mathrm{volume).} \mathrm{With}$ these three measurements, determination of the percent porosity was possible by [30]:

$$
P(\%)=\frac{m_{1}-m_{2}}{m_{1}-m_{3}}
$$

The microstructure and surface morphology of the PSi samples were investigated by a Hitachi S-4800 scanning electron microscope (SEM) with Energy Dispersive X-Ray (EDX) detector. The presence of deposited layers on PSi samples was confirmed by EDX analysis. The crystalline nature and the phases of the $\mathrm{TiO}_{2}$ coated PSi samples were studied by a Philips X'Pert MPD X-ray diffraction (XRD) instrument with $\mathrm{CuK} \alpha$ of $1.54056 \AA$. Photovoltaic measurements employed an AM 1.5 solar simulator (Luzchem Research) at $25{ }^{\circ} \mathrm{C}$ equipped with an Autolab PGSTAT302 N potentiostat/galvanostat. The power of the simulated white light was calibrated to $100 \mathrm{~mW} / \mathrm{cm}^{2}$. Electrochemical impedance spectra (EIS) measurements were taken over a frequency range of $0.1 \mathrm{~Hz}-100 \mathrm{kHz}$ with $10 \mathrm{mV}$ amplitude at open-circuit conditions under standard global AM 1.5 solar irradiation. Reflectance of the obtained PSi samples was evaluated by reflectance spectroscopy measurements using an avantes spectrometer (Avaspec-2048-TEC). The amount of dye was determined by desorbing the attached dye molecules of the substrates in $0.1 \mathrm{M} \mathrm{NaOH}$ aqueous solution, with the concentration measured by a UV-Visible spectrophotometer (Perkin Elmer, Lambda 25).

\section{Results and Discussion}

\subsection{Microstructural Characterizations}

Porosity level, geometry, and microstructure of pores depend on the anodization conditions. These conditions include electrolyte concentration, etching current density, etching time, silicon wafer characteristic, illumination (required for n-type silicon), and 
Table 1. Experimental conditions of different PSi samples.

\begin{tabular}{|c|c|c|c|c|c|c|c|c|}
\hline Samples & parameters & Orientation & $\begin{array}{l}\text { Resistivity } \\
(\Omega \text {-cm) }\end{array}$ & $\mathrm{T}\left({ }^{\circ} \mathrm{C}\right)$ & $\begin{array}{l}\text { Time } \\
(\mathrm{min})\end{array}$ & $\begin{array}{l}\text { Current density } \\
\left(\mathrm{mA} / \mathrm{cm}^{2}\right)\end{array}$ & $\begin{array}{c}\text { (HF: Ethanol: DI) } \\
\text { solution }\end{array}$ & Porosity \\
\hline & PSi (I) & $\begin{array}{c}<111> \\
\mathrm{n}-\mathrm{Si}\end{array}$ & $1.5 \pm 0.2$ & 40 & 30 & 24 & (25\%: 60\%: 15\%) & $51 \%$ \\
\hline & PSi (II) & $\begin{array}{c}<100> \\
\mathrm{n}-\mathrm{Si}\end{array}$ & $1.5 \pm 0.2$ & 40 & 15 & 24 & (25\%: 60\%: 15\%) & $53 \%$ \\
\hline & PSi (III) & $\begin{array}{c}<100> \\
\mathrm{n}-\mathrm{Si}\end{array}$ & $1.5 \pm 0.2$ & 40 & 30 & 24 & (25\%: 60\%: 15\%) & $64 \%$ \\
\hline
\end{tabular}

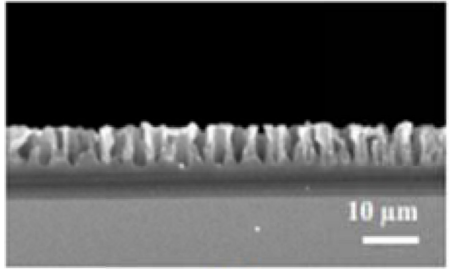

(a)

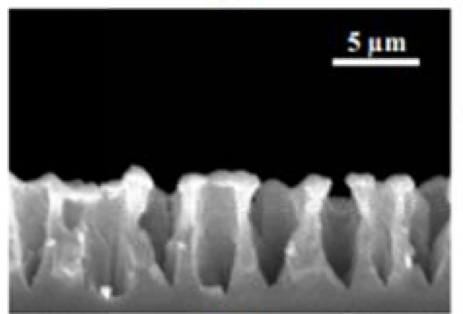

(b)

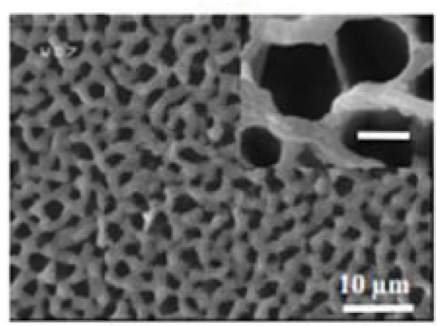

(c)

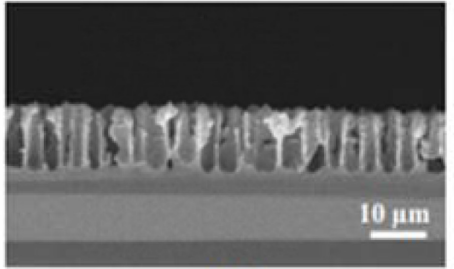

(d)

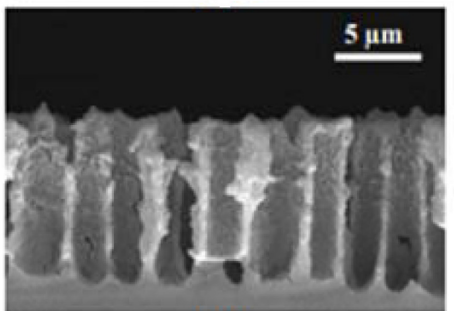

(e)

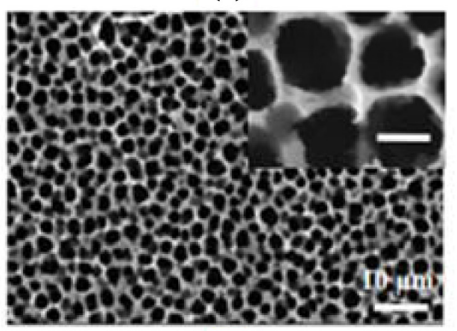

(f)

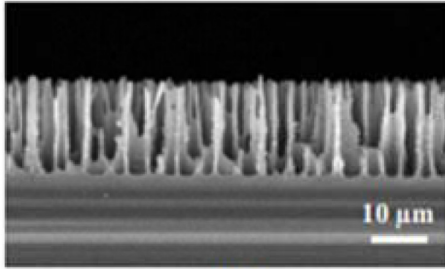

(g)

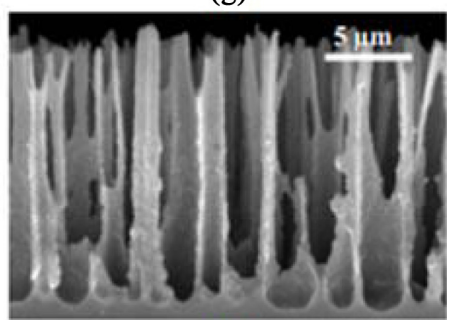

(h)

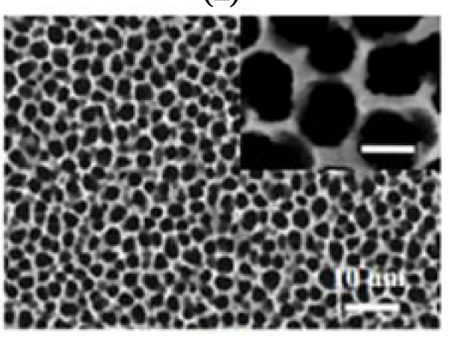

(i)

Fig. 1. Cross-sectional and top view SEM images of the PSi samples fabricated using the proposed electrochemical anodization method at different etching conditions: (a,b,c) PSi(I), (e,f,g) PSi(II), and (h,i,j) PSi(III). Inset scale bars are $3 \mu \mathrm{m}$.

temperature. Table 1 summarizes the experimental conditions of the three PSi samples which prepared in this investigation. In order to yield a better wetting properties of the Si surface, the compositions of the etch solution was (HF: Ethanol: DI $)=(25 \%$ : $60 \%$ : $15 \%)$. Also the etch temperature was $40{ }^{\circ} \mathrm{C}$ and all samples were made porous electrochemically by constant $24 \mathrm{~mA} / \mathrm{cm}^{2}$ current density when exposed to the white light. Fig. 1 shows the SEM images of three PSi samples fabricated using the proposed electrochemical anodization method at the different etching conditions. For PSi(I), the V-shaped structure at the bottom of the pores and hexagonal shape at the surface is because of (111) wafer orientation. Cross-sectional SEM images clearly demonstrate the pores size (diameter on top) in the range of 3-4 $\mu \mathrm{m}$ and their 


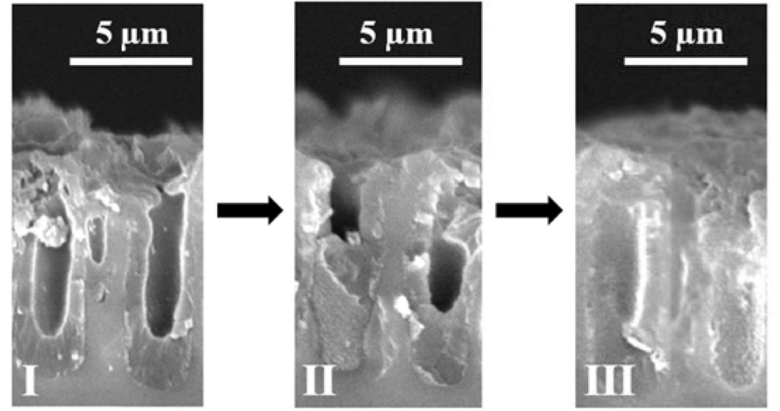

(a)

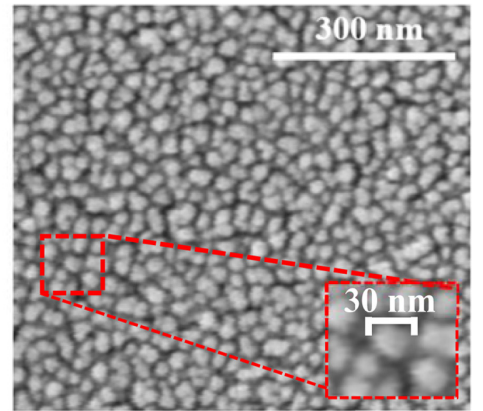

(b)

Fig. 2. (a) SEM images of the $\mathrm{TiO}_{2}$ film deposited on PSi(II) by sol-gel spin coating method: I) 5 spin-coating times, II) 10 spin-coating times, III) after filling of the pores (b) High magnification SEM image of $\mathrm{TiO}_{2}$ film (inset: $30 \mathrm{~nm} \mathrm{TiO}_{2}$ particle).

depth about $5 \mu \mathrm{m}$. For PSi(II) and PSi(III), the curveshaped structure at the bottom of the pores and circular shape at the surface is an outcome from the (100) wafer crystal orientation. Top-viewed SEM images (Fig. 1f, i) revealed that for both of these samples the pores diameter is the same and equals to $3 \mu \mathrm{m}$. The increase of the pores depth by growing the etching time is clearly visible in the cross-sectional images (Fig. 1e, h). For PSi(II) with 15 min time etching, the macro-pores length is about $10 \mu \mathrm{m}$, while it's approximately $15 \mu \mathrm{m}$ for PSi(III) which had 25 min time etching. Despite having the same etching condition, PSi(I) compared with PSi(III) has pores with less depth since the (111)-oriented planes slowly etch in the etching solution. The pore size, depth, and distribution are largely uniform and reproducible across the all three samples. Also, by Using gravimetrical technique the percent porosity values of $51 \%, 53 \%$ and $64 \%$ is calculated for PSi(I), PSi(II) and PSi(III) respectively.

The ITO films with a thickness of $300 \mathrm{~nm}$ were deposited on PSi samples by DC magnetron sputtering technique, as described previously [34]. The electrical properties of the ITO films were determined by the four-point probe technique. The measured values demonstrate the sheet resistance of ITO/PSi structures in the range of $8-10 \mathrm{ohm} / \mathrm{sq}$. As mentioned before, the $\mathrm{TiO}_{2}$ films prepared using sol-gel spin-coating method and annealed at $400^{\circ} \mathrm{C}$. As an example, three steps of the $\mathrm{TiO}_{2}$ film deposition on PSi(II) by spin coating method are shown in Fig. 2a. Cross-sectional SEM images of the $\mathrm{TiO}_{2}$ film after 5 spin-coating times, 10 spin-coating

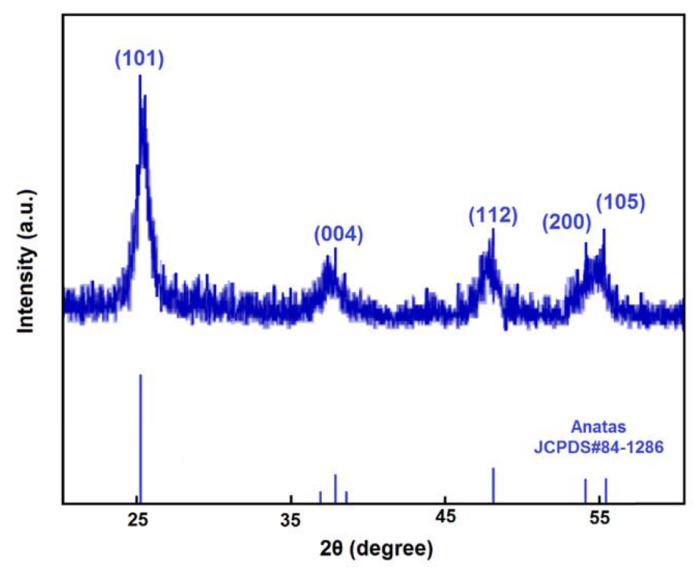

Fig. 3. X-ray diffraction patterns of sol-gel spin-coated $\mathrm{TiO}_{2}$ films.

times, and filling of the pores are respectively illustrated in Fig.2a-I, 2a-II, and 2a-III. Also High magnification SEM image of $\mathrm{TiO}_{2}$ film is shown in Fig. b. This image depicts nano-scale spherical particles of the film. The $\mathrm{TiO}_{2}$ grain size was observed to be about $30 \mathrm{~nm}$. The formation of nano-sized smooth grains all over the surface can lead to improve the dye-loading capacity due to larger surface area. The crystal phase of $\mathrm{TiO}_{2}$ films was determined by X-ray measurements. As XRD pattern depicts the spin-coated $\mathrm{TiO}_{2}$ layer is largely in anatase phase (Fig. 3). This layer shows predominant anatase peaks at (101), (004), (112), (200), and (105). All peaks are in good agreement with the standard spectrum (JCPDS no.: 88-1175 and 841286). For dye-sensitized solar cells, anatase is per- 
ceived as the more active phase of $\mathrm{TiO}_{2}$ because of its surface chemistry and potentially higher conduction-band edge energy [35].

Elemental analyses of PSi samples based on Energy-dispersive X-ray spectroscopy (EDX) were also performed at various steps of the fabrication process (Fig. 4). A single peak at $1.74 \mathrm{Kev}$ corresponding to $\mathrm{Si}$ was observed in the elemental analysis of $\mathrm{Si}$ wafer after electrochemical etching (Fig. 4(I)). The elemental analysis of ITO deposited on PSi sample (Fig. 4(II)) represents the presence of tin (Sn) and indium (In) distributed all over the porous substrate. Fig. 4(III) shows the EDX spectrum of sol-gel $\mathrm{TiO}_{2}$ film deposited on ITO coated PSi sample. The observed peaks at about $0.5,4.5$, and $4.95 \mathrm{KeV}$ in this spectrum, which are assigned to $\mathrm{O}$ and $\mathrm{Ti}$, demonstrate that this film is essentially pure.

\subsection{DSSC performance of PSi-based photoanodes}

Using the aforementioned samples as photoanode, three DSSCs were prepared and tested under $100 \mathrm{~mW} / \mathrm{cm}^{2}$ sunlight. In order to evaluate the performance of these cells, a conventional ITO-glass photoanode with the same manufacturing process was made, too. Fig. 4 shows the photocurrent density versus potential curves of the cells. In addition, the resulting photovoltaic parameters derived from the J$\mathrm{V}$ curves (Table 2). Power conversion efficiency values are $4.06 \%, 4.93 \%, 4.75 \%$ and $5.77 \%$ for photoanodes named as ITO-glass, PSi(I), PSi(II), and PSi(III), respectively. Comparing the photovoltaic performance parameters of the PSi-based DSSCs to the conventional DSSC, the PSi photoanodes in spite of the illumination through the counter-electrode are more photoactive than typical photoanode. Specially,

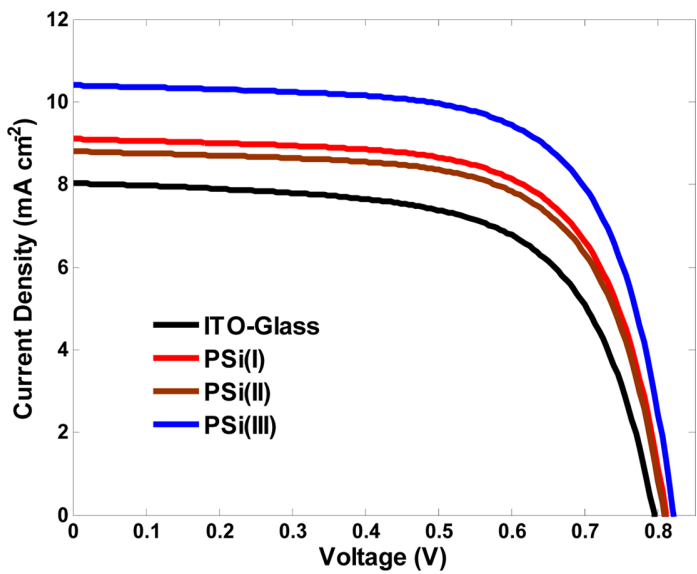

Fig. 5. Current-voltage characteristics of DSSCs fabricated using different PSi samples.
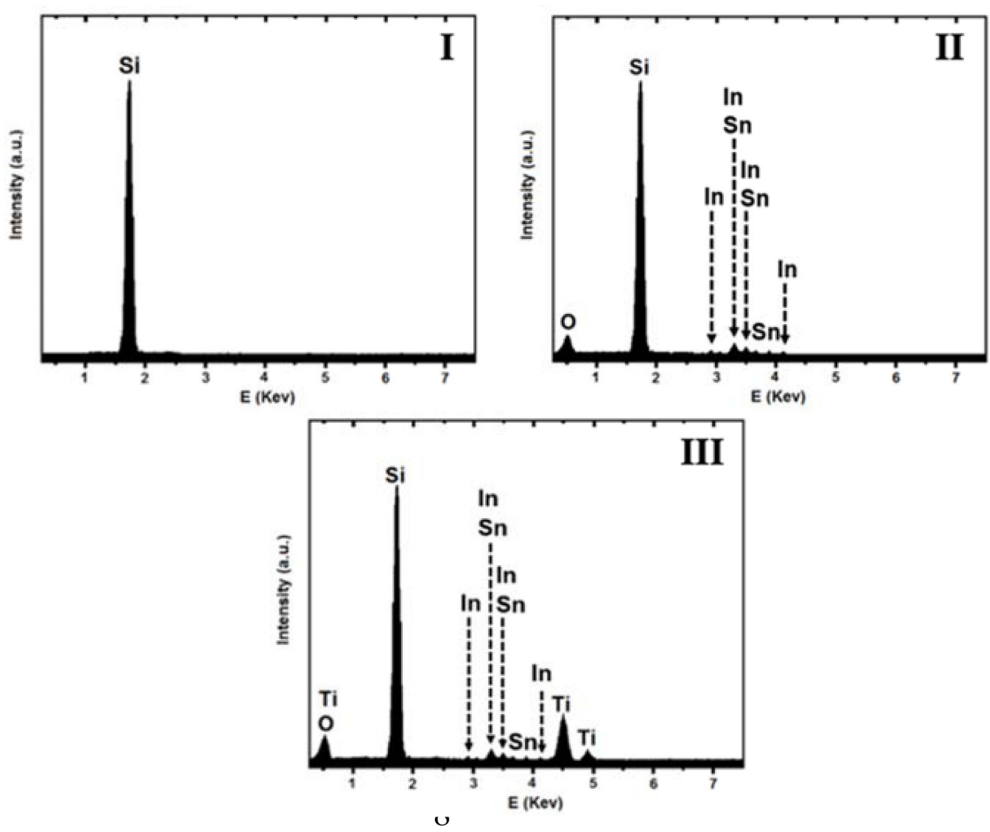

Fig. 4. EDX spectrum of I) freshly prepared PSi sample, II) ITO deposited PSi sample, III) sol-gel spin-coated $\mathrm{TiO}_{2}$ film on ITO coated PSi sample. 
the PSi(III)-based DSSC with deeper pores yielded a relatively large short-circuit photocurrent density $\mathrm{J}_{\mathrm{SC}}$ of $10.4 \mathrm{mAcm}^{-2}$, which is higher than $8.03 \mathrm{mAcm}^{-2}$ of the typical DSSC.

It shows that the characteristics of macro-porous layer such as the size and depth of pores have a considerable impact on the efficiency. This improvement is attributed to the higher LHE of the novel photoanodes which is an effective factor for raising the $\mathrm{J}_{\mathrm{SC}}$. This parameter is predominantly related to photoanode's optical properties and dye-loading capacity.

Table 2. Photovoltaic performance of the DSSCs using various types of photoanodes.

\begin{tabular}{ccccc}
\hline Photoanode & $\mathrm{J}_{\mathrm{SC}}\left(\mathrm{mAcm}^{-2}\right)$ & $\mathrm{V}_{\mathrm{OC}}(\mathrm{mV})$ & $\mathrm{FF}$ & $\eta(\%)$ \\
\hline ITO-glass & 8.03 & 794 & 0.635 & 4.06 \\
PSi(I) & 9 & 810 & 0.670 & 4.93 \\
PSi(II) & 8.8 & 807 & 0.668 & 4.75 \\
PSi(III) & 10.4 & 820 & 0.677 & 5.77 \\
\hline
\end{tabular}

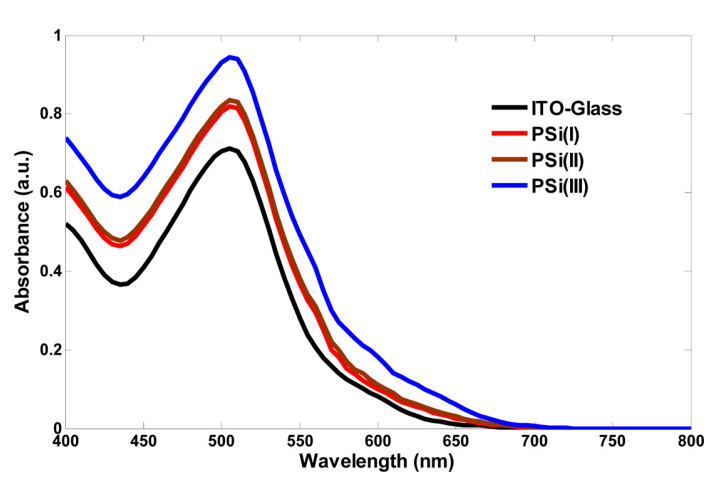

Fig. 6. UV/vis absorption spectra representing the amoun of dyes adsorbed in different photoanodes.

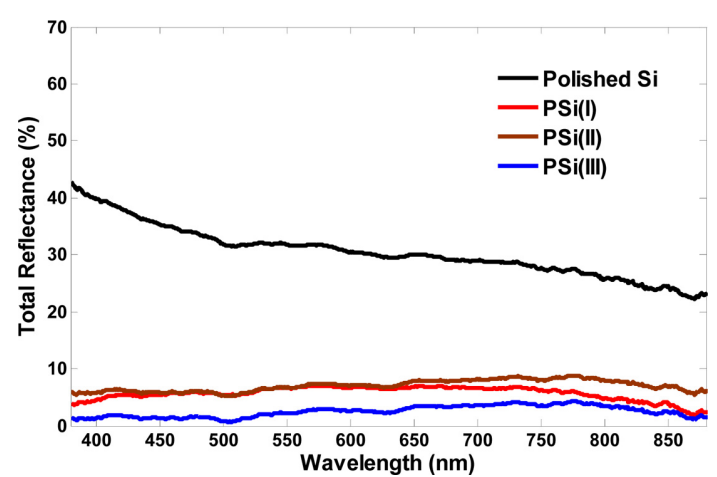

Fig. 7. Reflectance of the obtained PSi samples and the polished silicon wafer.
UV-visible experiments were carried out to verify the influence of PSi structures on the amount of dye adsorption. We characterized the amount of dye adsorbed after detaching the dyes from four photoanodes with $0.1 \mathrm{M} \mathrm{NaOH}$ aqueous solution. The resultant UV-visible data are shown in Fig. 6. According to the spectra, the spectral line shapes have the same trends for all photoanodes. It is clear from this figure that light absorption is increased in PSi-based photoanodes in a wide spectral range of 400-700 nm compared to the conventional ITO glass-based photoanode. Among different PSi-based photoanodes, PSi(III) has the highest amount of dye-loading capacity. This increment is due to the high surface area to volume ratio of PSi, the percent porosity value of $64 \%$, which makes more surfaces available for $\mathrm{TiO}_{2}$. On the basis of this finding, we conclude that the presence of the PSi structures affects the dyeloading capacity considerably and thus they were found to have better photovoltaic performance than the conventional ITO-glass photoanode.

For investigating the possible light trapping effects, the diffuse reflectance of the prepared PSi samples was measured on a UV/Vis/NIR spectrophotometer. Fig. 7 shows the diffuse reflectance of the prepared PSi samples and polished single-crystal silicon wafer. It clearly shows that PSi structures drastically suppress light reflection over a wide spectral bandwidth. The average reflectance of the polished wafer, PSi(I), PSi(II) and PSi(III) in the wavelength range of 300$900 \mathrm{~nm}$ are about $35 \%, 5.7 \%, 7 \%$, and $3.5 \%$ respectively. This remarkably low broadband reflectance indi-

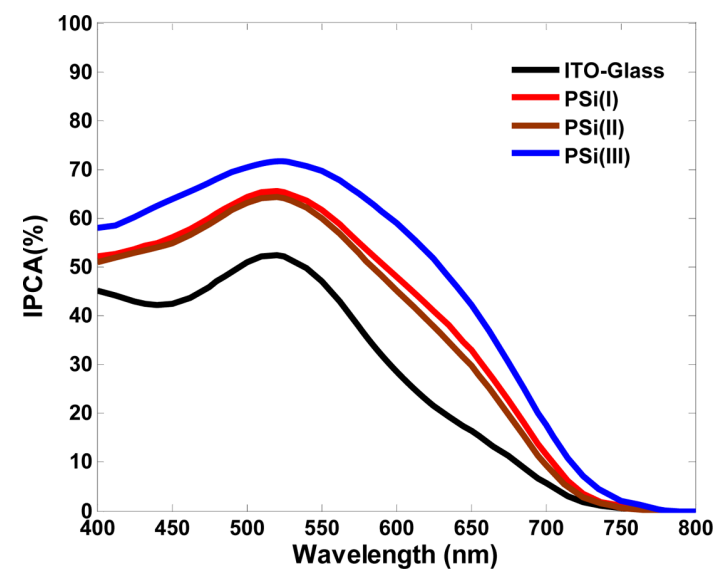

Fig. 8. IPCE versus wavelength for DSSCs employing different PSi samples. 


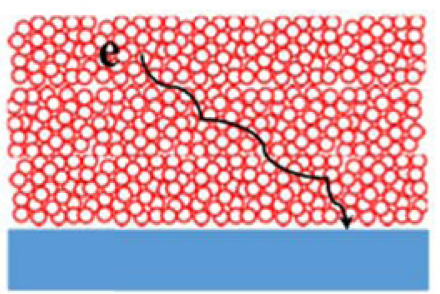

(a)

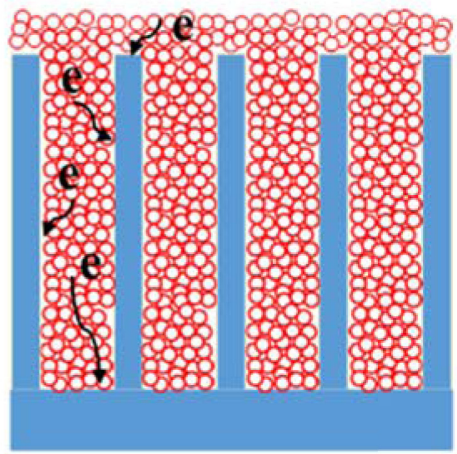

(b)

Fig. 9. Electron transfer through $\mathrm{TiO}_{2}$ nanoparticles in: (a) conventional photoanode, (b) PSi photoanode.

cates excellent light trapping ability of PSi structures which can be a major cause of improved photovoltaic performance of PSi-based DSSCs. Topographically rough, vertically aligned macro-porous structure may help to trap the light better and thus enhances the probability of photon absorption by the dye molecules. PSi(III) has significantly lower reflectance in comparison with two other samples that is due to deeper pores of this sample. Lower reflectance of PSi(I) compared to PSi(II), despite having shallower pores, can be an outcome from its pores' shape. By comparing Table 2 and Fig. 6 , it is concluded that there is a direct relationship between anti-reflective property and power conversion efficiency.

The incident photon-to-current efficiency (IPCE) spectra for each DSSC are presented in Fig. 8. As expected, the quantum efficiency in the visible region of light for each PSi-based DSSC is higher than that of the conventional DSSC. Moreover, the PSi(III)based photoanode exhibits higher IPCE than PSi(I) and PSi(II) photoanodes, which is attributed to its greater dye adsorption and Lower reflectance properties. These results have good consistency with the aforementioned dye-loading and reflectance data.

It is noteworthy that the introduction of PSi photoanode into the DSSC not only improves the LHE but also reduces the electron-hole recombination rate in the $\mathrm{TiO}_{2}$ layer. Schematic diagrams for the possible electron transferring in two types of photoanode structures are shown in Fig. 9. In conventional photoanode (Fig. 9a), without macro-pore structures, electrons that are injected into $\mathrm{TiO}_{2}$ nanoparticles may transfer around and need a much longer transfer dis-

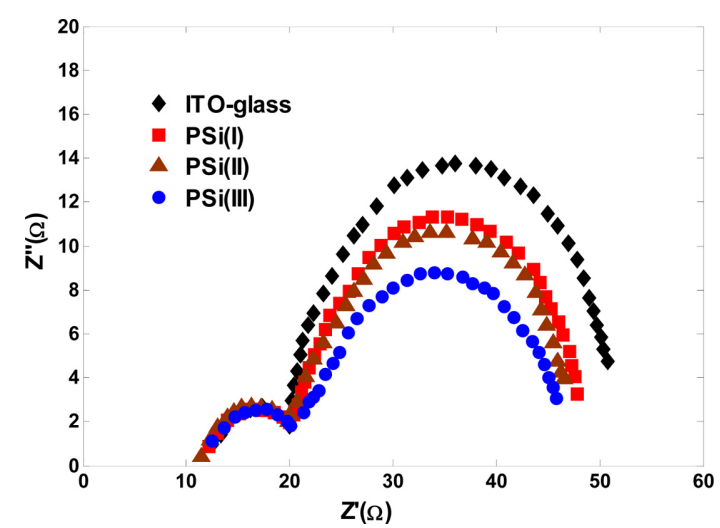

Fig. 10. EIS spectra of DSSCs with various PSi photoanodes.

tance. But as depicted in Fig. 9b, PSi photoanodes due to their vertically aligned macro-pores provide more pathways for electrons without increasing their transport distance in the $\mathrm{TiO}_{2}$ layer, thus reducing the chance of charge recombination, which also means that the electrons transfer efficiently. For analyzing the charge transfer and recombination processes at the $\mathrm{TiO}_{2} /$ dye/electrolyte/Pt interfaces in DSSCs, EIS measurements were performed under AM 1.5 solar illumination and the results are shown in Fig. 10. Two semicircles extending from total series resistance are observed in high and middle frequency regions (left to right). The small semicircle $\left(Z_{\mathrm{CT}}\right)$ in the high frequency region is attributed to the impedance corresponding to the charge transfer process occurring at the electrolyte/Pt interface, while the large semicircle $\left(\mathrm{Z}_{\mathrm{TiO} 2}\right)$ in the low frequency region is 
attributed to the charge transfer and recombination at the $\mathrm{TiO}_{2} /$ dye/electrolyte interface [36-38]. As shown in Fig. 10, the radius of the large semicircle located in low frequency region in the Nyquist plots decreases for DSSCs employing PSi-based photoanode compared with ITO glass-based DSSC. The radius values are in the order of PSi(III) $<$ PSi(II) $<$ PSi(I) $<$ ITO-glass, which indicates a decrease of the electron transfer impedance $\left(\mathrm{Z}_{\mathrm{TiO} 2}\right)$ and an increase of charge transfer rate at this interface. This is how the vertically aligned macro-pores facilitate interfacial charge transfer and thus lower the charge recombination. In particular, the PSi(III)-based DSSC has the smallest interfacial impedance, which implies the fastest interfacial electron transfer and thereby rendering the highest power conversion efficiency.

The fill factor (FF) is the ratio of the maximum power from the DSSC to the product of $\mathrm{V}_{\mathrm{oc}}$ and $\mathrm{J}_{\mathrm{sc}}$. The value of the FF depends on the normalized open circuit voltage [39]. A higher voltage will have a higher possible FF and the JV curve of the DSSC will be more approached a rectangle. The $\mathrm{V}_{\mathrm{oc}}$ is the difference between the Nernstian potential of the solution and the semiconductor's quasi-Fermi level. At open circuit, the rates of electron injection and recombination/interception are equal, and their values determine the steady-state electron concentration in the semiconductor and therefore its quasi-Fermi level. The quasi-Fermi level, and thus $\mathrm{V}_{\mathrm{oc}}$, can be increased by enhancing the rate of electron injection $\left(\mathrm{J}_{\mathrm{sc}}\right)$ or decreasing the rate of electron recombination/interception. In the case of our devices, as shown in table 2 , cells incorporated with PSi exhibit higher $\mathrm{V}_{\mathrm{oc}}$ and thus FF. This can be attributed to the following factors: first, as depicted in Fig. 6 and 7, PSi structures drastically suppress light reflection and enhance dyeloading capacity. These properties provide the photons with more opportunities to be absorbed by the dye molecules, results in a significant improvement in the rate of electron injection. Second, as shown in Fig. 10, the charge transfer impedance of the PSi based DSSCs is lower than that of the conventional DSSC. Thus, these results show that one can expect a lower recombination from the PSi electrode in comparison with the typical one.

\section{Conclusion}

This investigation presents a highly efficient and simple light trapping strategy by fabricating a novel macro-porous silicon based photoanode. The macroporous structures are prepared through a simple and cost effective electrochemical anodization method. The photoelectric measurements showed that the standard photovoltaic parameters for modified DSSCs including the short circuit current density, the fill factor, and the power conversion efficiency have remarkably increased compared with the values for a conventional DSSC. Among three different PSi geometries employed, the PSi(III) photoanode with more porosity percentage, shows the highest efficiency of $5.77 \%$ which is nearly two times higher than that of the conventional one. Surface reflectance, dye adsorption, and electrochemical impedance spectroscopy experiments notified that the vertically aligned macro-pore structures are the origin of the light harvesting efficiency improvement. The total light reflection is dramatically reduced by the increase of the light path length inside these structures, which leads to more photon absorption. Moreover, porous structures with large surface area allow higher rate of dye adsorption and assist in the interfacial charge transfer, which render higher photocurrent and lower charge recombination. Further adjustments can be performed in future to achieve optimal light trapping structures, which provide a good way to improve the overall power conversion efficiency of DSSCs.

\section{References}

[1] F. Sauvage, D. Chen, P. Comte, F. Huang, L. P Heiniger., Y. B. Cheng, R. A. Caruso and M. Gratzel, ACS Nano, 2010, 4(8), 4420-4425.

[2] T. K. Yun, S. S. Park, D. Kim, Y. K. Hwang, S. Huh, J. Y. Bae and Y. S. Won, J. Power Sources, 2011, 196(7), 3678-3682.

[3] X.-D. Gao, X.-M. Li, X.-Y. Gan, Y.-Q. Wu, R.-K. Zheng, C.-L. Wang, Z.-Y. Gu and P. He, J. Mater. Chem., 2012, 22(36), 18930-18938.

[4] S. H. Ko, D. Lee, H. W. Kang, K. H. Nam, J. Y. Yeo, S. J. Hong, C. P. Grigoropoulos and H. J. Sung, Nano Lett., 2011, 11(2), 666-671.

[5] J. Qiu, F. Zhuge, X. Li, X. Gao, X. Gan, L. Li, B. Weng, Z. Shi and Y. H. Hwang, J. Mater. Chem., 2012, 22(8), 3549-3554.

[6] S. M. Mahpeykar, J. Koohsorkhi and H. Ghafoori-fard, Nanotechnology, 2012, 23, 165602.

[7] H. J. Koo, J. Park, B. Yoo, K. Yoo, K. Kim and N. G. Park, Inorg. Chim. Acta, 2008, 361, 677-683. 
[8] K. Fan, W. Zhang, T. Peng, J. Chen and F. Yang, J. Phys. Chem. C, 2011, 115(34), 17213-17219.

[9] X. Liu, M. Guo, J. Cao, J. Lin, Y. H. Tsang, X. Chen and H. Haung, Nanoscale Research Letters, 2014, 9, 362.

[10] N. C. Jeong, C. Prasittichai and J. T. Hupp, Langmuir, 2011, 27(23), 14609-14614.

[11] M. D. Brown, T. Suteewong, R. S. S. Kumar, V. D. Innocenzo, A. Petrozza, M. M. Lee, U. Wiesner and $\mathrm{H}$. J. Snaith, Nano Lett., 2011, 11(2), 438-445.

[12] H. Choi, W. T. Chen and P. V. Kamat, ACS Nano, 2012 , 6(5), 4418-4427.

[13] B. Mandlmeier, J. M. Szeifert, D. Fattakhova-Rohlfing, H. Amenitsch and T. Bein, J. Am. Chem. Soc., 2011, 133, 17274-17282.

[14] A. Mihi, C. Zhang and P. V. Braun, Angew. Chem. Int Ed., 2011, 50, 5712-5715.

[15] W. Zhang, M. Anaya, G. Lozano, M. E. Calvo, M. B. Johnston, H. Miguez and H. J. Snaith, Nano Lett., 2015, 15, 1698-1702.

[16] E. Yablonovitch and G. D. Cody, IEEE Trans. Electron Dev., 1982, 29(2), 300-305.

[17] P. Campbell and M. A. Green, J. Appl. Phys., 1987, 62(1), 243-249.

[18] A. W. Smith and A. Rohatgi, Sol. Energy Mat. Sol. C., 1993, 29, 37-49.

[19] S. Q. Hussain, S. Ahn, H. Park, G. Kwon, J. Raja and Y. Lee, Vacuum, 2013, 94, 87-91.

[20] L. Chen, M. M. Alkaisi and M. Y. Liao, J. Nonlinear Optic. Phys. Mat., 2010, 19, 761-766.

[21] S. M. Kong, Y. Xiao, K. H. Kim, W. I. Lee and C. W. Chung, Thin Solid Films, 2011, 519, 3173-3176.

[22] S. Wooh, H. Yoon, J. Jung, Y. Lee, J. H. Koh, B. Lee, Y. S. Kang and K. Char, Adv. Mater, 2013, 25, 3111-3116.

[23] N. C. D. Nath, I. S. Jung, S.-W. Kim and J.-J. Lee, Sol. Energy, 2016, 134, 399-405.

[24] C. H. Lee, P. T. Hsiao, M. D. Lu and J. M. Wu, RSC
$A d v ., 2013,3,2216-2218$.

[25] C. Gerhards, C. Marckmann, R. Tolle, M. Spiegel, P. Fath, G. Willeke, E. Bucher, J. Creager and S. Narayanan, Proceedings of the $26^{\text {th }}$ IEEE Photovoltaic Specialists Conference, 1997, 43-46.

[26] W. A. Nositschka, C. Beneking, O. Voigt and H. Kurz, Sol. Energy Mat. Sol. C., 2003, 76(2), 155-166.

[27] L. A. Dobrzanski, A. Drygała, K. Gołombek, P. Panek, E. Bielanska and P. Zieba, J. Mater. Process. Tech., 2008, 201(1-3), 291-296.

[28] M. J. Sailor, Porous Silicon in Practice: Preparation, Characterization and Applications, Wiley, New York (2012).

[29] A. Langner, F. Muller, U. Gosele, O. Hayden, K. Nielsch (Eds.), Molecular- and Nano-Tubes, Springer, New York, 431 (2011).

[30] M. Nazari and S. Khatami, Sensor Mater, 2013, 25, 131-140.

[31] S. Ito, T. N. Murakami, P. Comte, P. Liska, C. Gratzel, M. K. Nazeeruddin and M. Gratzel, Thin Solid Films, 2008, 516, 4613-4619.

[32] Y. S. Jin, K. H. Kim and H. W. Choi, J. Korean Phys. Soc., 2010, 57, 1049-1053.

[33] A. Sharma, R. K. Karn and S. K. Pandiyan, Int. J. Appl. Eng. Res., 2013, 8, 2057-2066.

[34] M. Aliaghayee, H. Ghafoori Fard and A. Zandi, $J$. Porous Mater., 2015, 22, 1617-1626.

[35] N.-G. Park, J. van de Lagemaat and A. J. Frank, J. Phys. Chem. B, 2000, 104, 8989-8994.

[36] J. Bisquert, Phys. Chem. Chem. Phys., 2000, 2, 41854192.

[37] R. Kern, R. Sastrwan, J. Ferber, R. Stangl and J. Luther, Electrochim. Acta., 2002, 47, 4213-4225.

[38] Q. Wang, J.-E. Moser, and M. Gratzel, J. Phys. Chem. $B, \mathbf{2 0 0 5}, 109,14945-14953$.

[39] M. A. Green, Solid State Electronics, 1981, 24, 788-789. 